\title{
Evolved adaptation to low ultraviolet radiation may be the main cause of malignant melanoma independent of high ultraviolet radiation levels
}

\section{Wenpeng You}

The University of Adelaide Adelaide Medical School

\section{Renata Jolanta Henneberg}

The University of Adelaide Adelaide Medical School

\section{Brendon Coventry}

The University of Adelaide Adelaide Medical School

Maciej Henneberg ( $\square$ maciej.henneberg@adelaide.edu.au )

University of Adelaide https://orcid.org/0000-0003-1941-2286

Research article

Keywords: malignant melanoma, low ultraviolet radiation, melanin

Posted Date: July 9th, 2020

DOI: https://doi.org/10.21203/rs.3.rs-28249/v2

License: (c) (i) This work is licensed under a Creative Commons Attribution 4.0 International License.

Read Full License 


\section{Abstract}

Background: The low melanin production (depigmentation) evolved in response to low ultraviolet radiation may be the principal determinant of malignant melanoma of skin (C43).

Methods: Worldwide country-specific estimates of melanoma incidence, daily UVR levels, skin colour (EEL), socioeconomic status (GDP PPP), magnitude of reduced natural selection ( $\left.\mathrm{l}_{\mathrm{bs}}\right)$, ageing, urbanization, percentage of European descendants (Eu\%), and depigmentation measured by blonde hair colour, were subjected to statistical analyses. Data for 182 individual countries were derived from WHO, United Nations, World Bank databases and the literature. Parametric and non-parametric correlations, partial correlation analyses keeping confounders statistically constant, multivariate regressions and analyses of variance were used.

Results: Worldwide, UVR levels were in negative correlation with melanoma (C43) incidence ("rho" = $-0.515, p<0.001)$. This relationship remained significant and negative in parametric partial correlation $(r=$ $-0.513, p<0.001)$ when GDP PPP, $I_{b s}$, ageing and urbanization were statistically kept constant.

In stepwise linear regression analysis, UVR was the variable having greatest negative influence on melanoma incidence $\left(R^{2}=0.301\right)$.

Melanoma incidence was in strong correlation with Eu\% $(r=0.711, p<0.001)$. The negative relationship between melanoma and UVR levels $(r=-0.498, r<0.001)$ and positive relationship of melanoma with Eu\% $(r=0.477, p<0.001)$ remained significant in partial correlation analyses.

When melanoma incidence rate was standardised on Eu\% it did not correlate at all with UVR ("rho" $=0.004$, $p=0.967, n=127)$. The country-specific depigmentation level strongly correlated with melanoma incidence $(r=0.705, p<0.001, n=48)$ remaining significant in partial correlation $(r=0.315, p<0.01)$. However, UVR showed nil no correlation with melanoma when depigmentation, together with the other four potential confounders was included as the controlled variable.

Conclusions: Low melanin production, genetically determined, that has adaptively evolved over generations represents the principal risk factor for melanoma, while UVR has a secondary role.

\section{Background}

Malignant melanoma of the skin [1] (WHO ICD: C43) is an interesting skin cancer particularly common in European individuals with depigmented skin types [2]. It is a malignancy of pigment-producing cells (melanocytes) which are primarily located in the skin [3] and also arises less commonly at internal mucosal sites and in low-pigmented areas, such as the hands and feet (acral). It represents a significant and growing public health burden worldwide. Globally, the melanoma incidence rate has been increasing over past decades [4]. Worldwide, in 2012, the incidence rate of melanoma (C43) reached 3.0 per 100,000 and, globally, an estimated 232,130 people developed C43 [5, 6]. Much effort has been made to 
investigate to what extent changes in behaviour, in the environment, or in early detection are involved, but the mechanism of the increasing incidence is still not well understood [4].

It has been reported that high melanoma incidence has occurred in people of European descent in last decades [6-10]. It is estimated that the annual increase in incidence rate of melanoma (C43) for European-derived populations remains much higher than for all other populations $[6,11]$. Therefore, typically European phenotypes, such as blond hair, light-coloured eyes, fair skin, sun-sensitive skin, more naevi (moles) [12] and freckles [13-16] have been considered as risk factors for melanoma.

Extensive studies have linked C43 risks to sunlight exposure-related behaviours, such as strong sun exposure in childhood [17, 18], sunburn episodes [19, 20], solarium use [21-23], and outdoor work [24]. Although the conclusions are largely associative and circumstantial, high UVR exposure has been commonly accepted as the primary risk factor for $\mathrm{C} 43$.

It has been accepted that exposure to intense UVR levels causes damage to the DNA of melanocytes, which constitutes the major contributor for developing C43 [25-31]. Although this theory has some supportive evidence, it poorly explains the true epidemiology of melanoma worldwide and the regional variations. For example, UVR in the Europe region of World Health Organization (WHO) is significantly lower than in other regions [32], but its melanoma incidence rate is significantly higher than other WHO regions [33].

Melanoma (C43) prevention campaigns have advocated sunscreen use to reduce the C43 risk [34]. Contrary to the campaign aims, some epidemiological studies have shown that sun-blocking substances, such as sunscreen lotion, do not protect against C43 development [35-37]. Surprisingly, studies have reported that individuals regularly applying sun block could have a higher risk of C43 than non-users [36, 38-40]. Therefore, the controversial role of sun-blocking products in protecting against melanoma development remains confusing and intriguing for professionals and lay-people [4, 36, 41].

Before high UVR exposure is unanimously accepted as the main risk factor for melanoma, researchers have started to debate whether intermittent [42] or chronic [43] sun exposure should be considered as important risks of melanoma. Several studies may make the debate pointless because they have revealed that subtypes of melanoma can develop in skin areas with little or no UVR exposure (i.e. mouth, soles of feet, palms of hands, mucosal sites, buttocks and genital areas) [2, 44]. It is well-known that occurrence of some melanoma subtypes (eg acral lentiginous) is not related to UVR exposure. A recent study published in Nature even revealed the whole-genome mutational profile of some melanoma subtypes could occur without sun exposure possibly extending to the non-coding genome [2].

Regardless of rare early melanoma onset in young people with fair pigmentation [45], ageing is a wellestablished risk factor, which may be partially attributable to more sun exposure $[13,17,46]$ as the sun exposure is cumulative over lifetime. 
From an evolutionary perspective, it has been known that human adaptation to low UVR exposure in Northern Europe over many generations resulted in decreased melanin production, most likely to permit sufficient vitamin D production in the skin in these environments [47]. During this micro-evolutionary process, recessive mutations/genes disabling normal melanin production for skin, hair and eye colouration were accumulated. This process may also be advantageous to folate and folic acid in human blood [48-50].

We advance the hypothesis that recessive mutations/genes arising during micro-evolutionary processes leading to strongly reduced ability to produce melanin, may easily undergo somatic mutations resulting in melanoma development. This hypothesis is tested using population-level data on human pigmentation and melanoma (C43) incidence obtained from international data-collection organizations which were then adjusted for ambient UVR levels and other potential confounding variables. Since databases contain global data, adequate separate study of melanoma subtypes was not feasible.

\section{Methods}

\section{Data Sources}

Country-specific data published by the agencies of the United Nations were downloaded for this ecological study.

1. The GLOBOCAN 2012 estimate of country specific Melanoma of the skin (WHO C43) incidence rate in both sexes [33]

GLOBOCAN provides contemporary population level estimates by cancer site and sex [51]. This project is conducted by the World Health Organization (WHO) cancer research agency, the International Agency for Research on Cancer (IARC).

As per the International Statistical Classification of Diseases and Related Health Problems (10th Revision (ICD-10)-2015-WHO Version for 2015), IARC clustered 10-types of malignant neoplasms of skin as the malignant melanoma of skin which is coded as C43.

C43 incidence rate is expressed as the number of persons who were diagnosed with melanoma (C43) in 2012 per 100,000 population. The C43 incidence reported as an age standardised rate at world level was selected for analyses. No incidence of separate types or subtypes of melanoma was available.

2. Country-specific skin reflectance (armpit) .Data on skin reflectance of various populations worldwide were previously studied and published $[48,49,52,53]$. We extracted the country-specific skin reflectance data relevant for each country from previous publications using the same file as analysed in Brace et al. [54]. No worldwide information on skin phototypes was available. 
3. The WHO Global Health Observatory $(\mathrm{GHO})$ data on the average daily ambient ultraviolet radiation (UVR) level (in $\mathrm{J} / \mathrm{m}^{2}$ ) and life expectancy at age 60-years [32]. UVR has been backdated by approximately 10 years (1997-2003) to reflect long exposure duration with delayed presentation of melanoma.

Ageing has been included as a potential confounder in this study as it has been linked to melanoma risk in a number of publications $[13,17,46]$. We have indexed ageing at the population level with the life expectancy at age 60 in 2010, which reflects the overall mortality after the age of 60 years.

4. The World Bank published data on per-capita GDP PPP and urbanization [55]

Socio-economic level has been associated with melanoma risk $[51,56]$. We have chosen per capita GDP purchasing power rate (GDP PPP in 2012 international \$) because it takes into account the relative cost of local goods, services and inflation rates of the country.

Urbanization has been postulated as a major C43 predictor [57] because it represents the major demographic shift entailing lifestyle changes [58-60]. Urbanization is expressed with the country-specific percentage of total population living in urban areas in 2012.

5. Country-specific magnitude of possible melanoma (C43) gene accumulation downloaded from a previous publication [61]. This accumulation is assumed to be the effect of decreasing selection pressure that is changing mutation/selection balance. The Biological State Index $\left(\mathrm{l}_{\mathrm{bs}}\right)$ has been constructed to measure the opportunity for natural selection at the population level [61-67 and the Supplementary Information].

6. The $\mathrm{C} 43$ incidence rates vary between geographical areas, with the highest rates in Europe $[33,51,62]$ and in countries with the greatest proportion of European descendants [6, 11,63-65]. Therefore, we have constructed the following two further variables concerning populations of European origin/ descendants.

1. Country-specific percentage of European descendants (Europeans \% hereinafter) was collected from the EuroStat for European countries [66], and government and non-EU government documents for the rest of the countries with European descendants.

2. The country grouping of the WHO Europe Region was singled out for analysing the correlation between UVR and melanoma. We also obtained the country-specific percentage of population with light hair [67] as the measurement of the magnitude of depigmentation (depigmentation level hereafter).

All the potential confounding variables (GDP PPP, $\mathrm{I}_{\mathrm{bs}}$, ageing and urbanization) and independent variables (Skin reflectance, UVR, Europeans \% and depigmentation level) were matched with the dependent variable, country-specific melanoma (C43) incidence rate. A set of data consisting of 182 countries has been obtained for our analysis. Each country was treated as an individual subject in this study. The number of countries for each individual variable may differ because not all the countries had 
uniformly available information due to various reasons. All data were extracted and saved in Microsoft Excel ${ }^{\circledR}$ for the analysis.

\section{Data analysis}

The data analysis proceeded in six steps:

1. Scatter plots were produced with the cross-country raw data in Microsoft Excel ${ }^{\circledR}$ to explore and visualize the strength, shape and direction of correlation between UVR levels and melanoma incidence worldwide. Points representing Australia and New Zealand appeared to be the outliers. However, we did not remove these two datum points as major outliers because they represented the truth that Australia and New Zealand have had the highest melanoma (C43) incidence rates although their UVR levels have not been the highest $[6,11,68]$.

Scatter plots were also produced to explore the relationships between the melanoma incidence and Europeans \% worldwide, country-specific UVR within WHO-Europe and depigmentation level within the European area respectively.

2. Nonparametric correlation analysis (Spearman's $\rho$ ) was conducted to evaluate the worldwide direction and strength of the correlation between melanoma and each independent and potentially confounding variable.

3. Partial correlation of Pearson's moment-product approach on log-transformed data was conducted to explore the worldwide correlations between melanoma (C43) and UVR and melanoma and skin

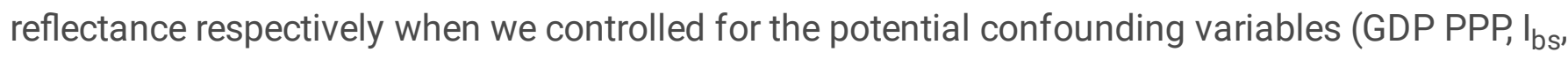
ageing and urbanization).

4. Standard multiple linear regression (Stepwise) was conducted on log-transformed variables to select the variables that had the greatest influence on melanoma incidence when UVR, $\mathrm{l}_{\mathrm{bs}}$, ageing, GDP PPP and Urbanization were entered as the independent variables.

Considering that melanoma has been constantly associated with people of European origin, we replaced UVR with the other two variables, "WHO EU Region" and "Europeans \%", respectively and repeated the above analyses (Step 2-4). In these two subsequent analyses, we did not analyse the relationship between the variable of skin reflectance and melanoma (C43) due to the very limited number of countries with available data in each data set.

Additionally, when we conducted the partial correlation within the dataset of "WHO EU Region", we alternated depigmentation and UVR as the control variable together with the other confounding variables (GDP PPP, $\mathrm{I}_{\mathrm{bs}}$, ageing and urbanization) to explore whether the variables UVR and depigmentation were correlated with melanoma (C43 incidence) independent of each other. Similarly, when we conducted the partial correlation with the dataset of "Europeans \%", we alternated Europeans \% and UVR as the control 
variables together with the other confounding variables (GDP PPP, $\mathrm{I}_{\mathrm{bs}}$, ageing and urbanization) to explore whether the variables UVR and EU\% correlated with C43 independent of each other.

5. Analysis of variance (ANOVA) was conducted to detect the significant differences between the six WHO regions among the means of melanoma (C43 incidence rate), and "Residual of C43 standardised on UVR" [69]. Further post-hoc (Bonferroni) testing was performed to identify the source (pairs) of the significant differences.

6. European population (WHO European Region) has the significantly higher incidence of $\mathrm{C} 43$ melanoma $[6,11,63,64]$, but significantly lower UVR levels than in all the other WHO regions. To examine whether, statistically, they can explain each other in terms of their worldwide relationships, we have used the analysis of residuals, because melanoma incidence is curvilinearly related to UVR and Europeans \%. Details in Supplementary Information.

Scatter plots, ANOVA and post hoc Bonferroni tests were conducted using the raw data. Nonparametric correlation, partial correlation of Pearson's moment-product and multiple linear regression analysis (stepwise) were conducted with SPSS v. 25 on the log transformed variables. The significance was kept at the 0.05 level, but 0.01 and 0.001 levels were also reported. Standard multiple linear regression analysis criteria were set at probability of $F$ to enter $\leq 0.05$ and probability of $F$ to remove $\geq 0.10$.

\section{Patient and Public Involvement}

This study does not directly involve any human participants or animals.

\section{Results}

Worldwide, the relationship between UVR and melanoma, identified in the scatterplots has been noted to be logarithmic with a relatively strong, but negative correlation $(r=-0.60, p<0.001, n=171$, Figure 1$)$. This indicates that people living in low solar ultraviolet radiation environments have higher C43 melanoma incidence.

Worldwide, UVR intensity was in significant and negative correlation with melanoma in non-parametric correlation analysis $(r=-0.52, p<0.001$, Table 1-1). This relationship remained negative and significant in partial correlation $(r=-0.51, p<0.001)$ when GDP PPP, $I_{b s}$, ageing and urbanization were statistically kept constant (Table 1-2).

Skin reflectance correlated positively with melanoma (C43) at a marginally significant level $(r=0.33$, $p=0.057, n=35$, Table 1-1). This correlation became weak $(r=0.15, r=0.505, d f=19)$ when GDP PPP, $l_{b s}$ ageing and urbanization were statistically kept constant (Table 1-2).

When UVR, GDP PPP, $\mathrm{I}_{\mathrm{bs}}$, ageing and urbanization were included as the predictor variables in stepwise linear regression analysis, UVR was selected as the variable having the greatest influence on melanoma 
incidence rate $\left(\mathrm{R}^{2}=0.30\right.$, Table $\left.1-3\right)$.

The ANOVA has revealed that WHO EU Region had significantly the highest mean melanoma incidence rate among other WHO regions while having the significantly lowest mean of UVR $\left(2189 \mathrm{~J} / \mathrm{m}^{2}\right)$. There were no significant differences between other regions (Table S1).

Worldwide, the relationship between Europeans \% and melanoma in the scatterplots was linear, with a positive relatively strong, correlation $(r=0.61, p<0.001, n=135$, Figure 2$)$.

Table 2-1 shows that melanoma incidence is in positive strong correlation with Europeans $\%(r=0.71$, $p<0.001)$ and in similarly strong, but negative correlation with UVR levels $(r=-0.70, r<0.001)$. In partial correlation analysis, these relationships between melanoma (C43) and Europeans \% $(r=0.48, p<0.001)$ and melanoma and UVR levels $(r=-0.50, r<0.001)$ remained significant when GDP PPP, $I_{b s}$, Ageing and Urbanization were statistically kept constant (Table 2-2).

Stepwise multiple linear regression analysis, including melanoma incidence rate as the dependent variable, and Europeans \%, UVR, GDP PPP, I $\mathrm{bs}_{\text {, }}$ Ageing and Urbanization as the independent variables, selected UVR as the variable having the greatest but negative influence on the melanoma incidence with $R^{2}=0.299$; while Europeans \% positive influence was placed second increasing $R^{2}$ to 0.336 (Table 2-3).

Figure 3 indicates that country-specific depigmentation level strongly correlates with melanoma (C43) incidence. (Power regression, $r=0.71, p<0.001, n=48$ ).

Table 3-1 shows that melanoma incidence is both in strong positive correlation with depigmentation $(r=$ $0.70, r<0.001$, Table 3-1) and in negative correlation with UVR irradiation $(r=-0.68, p<0.001$, Table 3-1). In partial correlation analysis these relationships between melanoma and depigmentation $(r=0.51, r<0.001$, Table 3-2) and melanoma and UVR $(r=-0.43, p<0.001$, Table 3-2) have remained significant when GDP PPP, $I_{b s}$, ageing and urbanization were statistically kept constant. Depigmentation still showed significant and positive correlation to $C 43(r=0.32, p<0.01$, Table 3-3), when UVR, together with other four potential confounders (GDP PPP, $\mathrm{I}_{\mathrm{bs}}$, ageing and urbanization), was included as the control variable. However, UVR showed almost nil correlation with melanoma incidence rate when depigmentation, together with the other four potential confounders (GDP PPP, $\mathrm{I}_{\mathrm{bs}}$, ageing and urbanization), was included as the controlled variable (Table 3-4).

This indicates that, statistically, depigmentation is a significant melanoma incidence rate predictor which is independent of UVR. In other words, it suggests that depigmentation may contribute to melanoma incidence rate without the contribution of UVR to this rate.

Within WHO EU, stepwise multiple regression analysis selected GDP PPP as the variable having the greatest influence on melanoma incidence rate while depigmentation was placed second (Table 3-5). However, UVR was removed by the analysis as having no statistically significant influence on melanoma 
incidence. This revealed that, statistically, the correlation between UVR and melanoma was dependent on depigmentation, but depigmentation correlated with melanoma (C43) independent of UVR.

\section{Discussion}

The GLOBOCAN data on melanoma incidence do not distinguish between subtypes of melanoma that may have different aetiologies, and place them all under the C43 label. This is why we have used the C43 label in our text to stress that we are discussing the whole range of subtypes jointly. According to Ward WH and Farma JM [70], the subtypes occur with following frequencies: superficial spreading $(70 \%$ of cases), nodular (5\%), lentigo-malignant (4-15\%), amelanotic (4\%), desmoplastic (less than $4 \%$ ) and acral lentiginous (5\%); of those, all but the last one are estimated on evidence to be UV induced, thus accounting for about $95 \%$ of all melanomas.

By examining the relationship between UVR and melanoma (C43) incidence across 182 countries, our analysis suggests that:

1. Countries with low UVR levels have high melanoma incidence rates.

2. Countries with greater percentage of European descendants have higher melanoma incidence rates.

3. When the percentage of European population is kept statistically constant there is no correlation between UVR level and melanoma incidence in a country.

4. In Europe, countries with high level of depigmentation have higher melanoma incidence rate. Country-level depigmentation negatively correlated with country-specific UVR levels indicating that depigmentation is a long-term evolutionary adaptation to low UVR.

From the perspective of human evolution, the magnitude of heritable depigmentation due to adaptation to low UVR exposure may predispose to melanoma incidence worldwide, while direct individual exposure to sunlight may play some causative role, that is, however, difficult to precisely quantify in population studies [71-74]. We have applied the modern evolutionary theory in order to interpret how human adaptation had produced the underlying cause for melanoma (C43) over a number of generations.

The findings of our study contradict the common opinion that high UVR exposure of individual humans is the primary risk factor for $\mathrm{C} 43$ [6, 75-78]. Biologically, the human body readily responds to changing environmental stresses, such as UVR, until the individuals are better adapted for improved physiological health and survival. There exist DNA repair mechanisms that remove mutagenic effects of UVR [79].The evolutionary adaptation process involves a mutation, or genetic change to make adapting traits inheritable. DNA methylation may also play an adaptive role [80-82]. Vitamin D is essential for maintaining strong bones and ensuring essential healthy functioning of the body including the lungs, cardiovascular system, immune system, and brain [83]. Although UVR only constitutes approximately $10 \%$ of the total light output of the sun, it is the best natural force for producing vitamin D. Melanin, produced in melanocytes, is able to dissipate more than $99.9 \%$ of UVR radiation absorbed by the skin [84]. More melanin in the skin not only protects the skin cells, including the pigment cells - melanocytes 
- against UV damage, but also protects against destruction of folate [48-50]. The natural consequence of high levels of melanin produced in the epidermis is inhibited synthesis of vitamin $D$ because of the lack of penetration of UV into the skin [85-87].

People living in areas with low UVR, would be advantaged by carrying the genes/ mutations which could alter their cell physiology for producing less melanin to allow better UVR penetration for better vitamin $D$ genesis and proper levels of folate [49]. Over generations, these mutations evolved into inheritable genetic signatures of populations with historically low UVR exposure [88, 89]. In people living for generations in areas with low-level of UVR exposure, the amount of melanin in human skin must be balanced between allowing enough UV penetration for the production of vitamin $D$ and preventing potential solar damage to skin cells [90].

Our study, statistically suggests that melanoma (C43) occurrence does not correlate with UVR levels at the country level. Historically, the negative correlation between UVR and melanoma indicates that low UVR, instead of too much UVR, may be the principal risk factor for melanoma. Europeans who live in the lowest UVR level countries have the highest melanoma incidence rates (Table 2, Figure 3). Also, extensive epidemiological studies of melanoma and demographic statistics have focused on the European populations.

Within the WHO Europe Region, melanoma incidence correlates positively with depigmentation, while it correlates negatively with UVR levels. The first relationship is independent of UVR exposure, but the latter is dependent on depigmentation. Further regression analyses imply that, statistically, 1) low UVR and Europeans \% explain each other for their contributing effects to melanoma; 2) if Europeans would have lived in any other WHO Region with higher UVR levels, their melanoma incidence may be at the similar level to Europe, and significantly different from people who have lived in that higher level UVR region for generations. Evolutionarily, low UVR has forced Europeans to depigment, and the genetically determined depigmentation may have made Europeans more susceptible to melanoma, independent of the environmental levels of UVR. The results of our study are in agreement with the finding that some melanoma subtypes can develop in skin areas with little or no UVR exposure[2, 44, 91]. A recent study has even revealed that whole-genome mutational landscapes of major melanoma subtypes could occur without UVR [2]. Also, in their study, Rampen and Fleuren postulate that melanoma may not be caused by UVR, but by xenobiotic influence [92]. Melanoma has been found to be familial [93] and highly heritable [94]. A number of genes predisposing to melanoma have been identified [95-100]. In a large study ( $\mathrm{N}=$ 100,000 ) published in 2019 , Ghiasvand and colleagues [71] have found that skin colour variation within the range displayed by Norwegian women produced melanoma risk ratios (RR) ranging from 1.53 for the head and neck to 2.32 for trunk, and freckling from 2.50 to 3.30 , while sun bathing produced RR from 0.41 to 1.71 and indoor tanning $0.85-1.18$. Clearly, the risk produced by depigmentation was approximately double that resulting from UVR exposure and significant for all body regions, not just some. 
Large-scale primary melanoma prevention programmes aiming at reduction of UVR exposure have not yet proven effective [35, 37, 101], or unexpectedly, have exacerbated C43 initiation [36, 38-40]. Some sunscreen skin lotions have been shown to have mild effects of reducing melanoma incidence [31], but their widely-publicised use did not stop the increase in the incidence of melanoma. This may be explained by our hypothesis that melanoma may primarily be a genetic disease of reduced pigmentation due to the long-term adaptation to low UVR, in order to aid vitamin D production [83], and only sometimes or partially initiated by UVR.

A key finding in this study is that, worldwide, countries with low UVR have the trend towards high C43 incidence. This is completely opposite to the current commonly accepted belief, "high UVR, high risk for C43" which has been primarily concluded from previous epidemiological studies in Australia and New Zealand. As shown in Figure 1, Australia and New Zealand have the highest melanoma incidence rates internationally (34.90 and 35.80 per 100,000 population respectively) [51], but their UVRs (3206 and 2487 $\mathrm{J} / \mathrm{m}^{2}$ respectively) are not the highest in the world being in fact comparable to Southern Europe, and much lower than in many countries with lower melanoma incidence rates [32].

Australians and New Zealanders are predominately European descendants, coming (temporally recently) mostly from Northern Europe that is Britain and Ireland. Australia and New Zealand do have somewhat higher UVR levels (3206 and $2487 \mathrm{~J} / \mathrm{m}^{2}$ respectively) than the whole of Europe $\left(2198 \mathrm{~J} / \mathrm{m}^{2}\right.$ ), while their melanoma incidence rates (34.90/100,000 and 35.80/100,000 respectively) are very much greater than in Europe $(7.53 / 100,000)$. While the UVRs in both Australia and New Zealand are lower than the worldwide mean UVR (3802 J/m²), their melanoma rates are much higher than the worldwide rate $(3.0 / 100,000)$. Although, there have been no clinical trials showing that high UVR causes melanoma [92], there is a "consensus" that high UVR is the primary risk factor for melanoma in Australia and New Zealand. We have considered several factors which may make the correlation of high UVR with high melanoma apparently spurious in Australia and New Zealand:

1) Australia and New Zealand have the highest rates of skin cancer incidence in the world, almost four times the rates registered in Canada, the United Kingdom and the United States of America [33] despite their UVR exposure being below the world average. Australians and New Zealanders have learned how to minimize sun exposure, how to seek cancer screening and self-diagnose skin cancers from a young age. For instance, skin cancer has been considered as a "National Cancer" [102]. This strong awareness of skin cancer, compounded by a high level of medical service delivery, has enabled Australians and New Zealanders to be diagnosed with more melanomas through self-diagnosis, cancer screening and vigilant medical diagnosis and early surgical removal. This may have increased incidence statistics in these locations. Indeed, potential over-diagnosis has been mooted [103].

2) Non-melanoma skin cancers (NMSC), most of which are basal cell carcinoma (BCC) and squamous cell carcinoma (SCC), account for over $98 \%$ of total skin cancers. Patients with BCC and/or SCC may have an increased risk for developing melanoma [104-108] and certainly have the highest possibility of 
early melanoma diagnosis because their skin is clinically assessed multiple times during BCC and SCC treatments.

3) The 5-year survival rate in melanoma is very high $(>90 \%)$ in Australia and New Zealand, while the history of melanoma has a definitive chance for reoccurrence [105]. Even "cured" patients with past melanoma are subject to a higher risk of developing a further new melanoma, making its incidence statistics even higher in these countries.

4) High levels of medical services and nutrition have substantially reduced natural selection. Almost all Australians and New Zealanders survive their full reproductive period, and they have the opportunity to pass on their melanoma-related mutations/genes and perhaps methylations to the next generation. When this process repeats for 4-5 generations, the C43 mutations/ genes accumulate and the phenotype of melanoma then becomes intensified and noticeable at the population level $[109,110]$.

5) Low fertility rates have been associated with cancer risks in both females and males [111-113]. Fertility rates in Australia and New Zealand are much lower than in many other countries. This may also partially explain the higher melanoma rates in these two countries.

It has been reported that vitamin D may protect against the development of cancers, including melanoma [114-116]. Although people who lived for generations in areas with low UVR exposure produce less melanin allowing more UVR to penetrate skin for better vitamin D genesis, they still have higher risk of developing melanoma. There may be two reasons: 1) Mutations have occurred in the genome of the people living in low UVR area, which made them prone to develop melanoma. Although those people could have favourable physiology for sufficient vitamin D production, they still have high risk of developing melanoma as a genetically determined disease. 2) Vitamin $D$ alone may not be capable of preventing melanoma occurrence. Moreover, Vitamin D receptor polymorphisms perhaps associated with depigmentation have been proposed, and lower Vitamin $D$ levels have been associated with poorer melanoma patient survival outcomes, which underline the importance and complexity of Vitamin D metabolism in melanoma pathophysiology $[117,118]$.

In our study, skin reflectance correlated with melanoma incidence $(r=0.33, p=0.057, n=35)$ at a similar level, but positively, as compared to the negative correlation of UVR with C43 $(r=-0.52, r<0.001, n=171)$ in non-parametric analysis. However, the former correlation between armpit skin reflectance and melanoma incidence lost its significance and became weak $(r=0.15, p=0.505 \mathrm{df}=19)$ in the subsequent partial correlation. The explanations could be: 1) The smaller sample size of armpit skin reflectance. 2) Armpit skin reflectance may not be a precise measure of melanin production in the skin because of a great variability of skin colour on different body sites and in different seasons [119-121]. Pigmentation may vary $70-100 \%$ in the skin of the same person [122]. Therefore, pigmentation of UVR unexposed skin, including the armpit or inside of the upper arm cannot fully represent the constitutive skin pigmentation [122-125]. 
In terms of disease prevention, or treatment, it is advantageous to know its extraneous causes as such can be easily removed or controlled. In many cancers, however, such causes are not known, while genetic susceptibility plays a role [89]. Cancers are related to somatic mutations [126-128]. These can occur randomly as a result of chance alterations of DNA structure that depend only on this structure's physicochemical properties [129-132] while their expression may be regulated by tumour suppression [133], methylation [134], DNA repair mechanisms and immune responses. It seems that the major cause of melanoma are DNA structures that evolved as a result of low UV adaptations allowing advantageous corrections of levels of vitamin D and folates to be maintained. Specific UVR exposure may play a role in triggering some of the somatic mutations, or modulation of their expression, however some somatic mutations can occur without UVR exposure.

\section{Conclusion}

High UVR levels do not explain melanoma epidemiology regionally or globally. Our study suggests that genetic coding related to low melanin production in the skin, which evolved as a genetic adaptive trait to chronic low UVR exposure over generations, is the primary risk factor for melanoma (C43).

Progressively evolving genetic melanin-loss, causing depigmentation, in low-UV level regions over time offers significant adaptive advantage through better physiological vitamin $D$ and folate levels for perireproductive health, at the consequent cost of higher risk of melanoma and skin cancer development, borne mostly post-reproductively, and also with greater UV susceptibility even at low intensities.

\section{What is already known on this topic}

Human adaptations to changing environments, such as ultraviolet radiation, result from alterations of the genetic code. The amount of melanin produced in the skin is inversely related to the ultraviolet radiation in areas where human populations have lived over generations.

The whole-genome landscapes of major malignant melanoma subtypes have revealed that they could occur without sun exposure.

Reduction of skin exposure to ultraviolet radiation may not prevent incidence of malignant melanoma.

\section{What this study adds}

Statistically, populations living in the low ultraviolet radiation environments have greater risk of developing malignant melanoma than those in high ultraviolet radiation regions.

Malignant melanoma is a genetic disease resulting from the natural selection for low melanin production genes causing depigmentation in environments with low ultraviolet radiation exposure.

Genes for low melanin production in the normal skin may be prone to somatic mutations and methylation causing malignant melanoma. 


\section{Declarations}

\section{Ethics approval and consent to participate}

This study does not involve any human participants or animals. Ethical approval is not required.

\section{Availability of data and material}

All data for this study are publicly available from the United Agencies' websites. The purpose of using these in this study meets the terms and conditions of the relevant UN agencies. The formal permission is not required to download and analyse the data in this study. The data sources have been detailed in the "Materials and Methods".

\section{Consent for publication}

Not applicable.

\section{Funding}

There is no specific funding support for this study.

\section{Competing interests}

The authors have no competing interests to declare.

\section{Authors' contributions}

$\mathrm{MH}$ conceived the hypothesis and study design, and $\mathrm{WY}$ and $\mathrm{MH}$ collected the data and conducted the analyses. WY, RH, BJC and $\mathrm{MH}$ interpreted the data. $\mathrm{RH}, \mathrm{BJC}$ and $\mathrm{MH}$ provided inputs for WY to draft and revise the manuscript. All authors reviewed, edited and approved the final manuscript.

\section{Acknowledgments}

We thank Dr John Relethford for providing a large part of data on skin colour.

\section{Abbreviations}

WHO: World Health Organization

ICD: International Classification of Diseases 
C43: Malignant melanoma coded as C43 as per International Classification of Diseases

UN: The United Nations

$\mathrm{I}_{\mathrm{bs}}:$ Biological State Index

GDP PPP: Gross domestic product at Purchasing Power Parity

UVR: Ultraviolet radiation exposure

SES: Socioeconomic status

BCC: basal cell carcinoma

SCC: squamous cell carcinoma

\section{References}

1. International Agency for Research on Cancer. Cancer. 201722 December 2017]; Available from: http://globocan.iarc.fr/Pages/cancer.aspx.

2. Hayward, N.K., et al., Whole-genome landscapes of major melanoma subtypes. Nature, 2017. 545(7653): p. 175-180.

3. National Cancer Institute, Melanoma Treatment (PDQ®) Health Professional Version (March 22, 2018).

4. Berwick, M. and C. Wiggins, The current epidemiology of cutaneous malignant melanoma. Front Biosci, 2006. 11(1): p. 1244-1254.

5. IARC-WHO. DataSource_and_methods. 2017; Available from: http://globocan.iarc.fr/Pages/DataSource_and_methods.aspx\#.

6. Stewart, B.W., World Cancer Report 2014. 2014, Lyon: Lyon, FRA: International Agency for Research on Cancer.

7. Azoury, S.C. and J.R. Lange, Epidemiology, risk factors, prevention, and early detection of melanoma. Surgical Clinics, 2014. 94(5): p. 945-962.

8. Armstrong, B. and A. Kricker, How much melanoma is caused by sun exposure? Melanoma research, 1993. 3(6): p. 395-401.

9. La Vecchia, C., et al., Recent declines in worldwide mortality from cutaneous melanoma in youth and middle age. International journal of cancer, 1999. 81(1): p. 62-66.

10. Coleman, M., et al., Melanoma of the skin. Trends in cancer incidence and mortality, 1993. 121(16): p. 379-401.

11. Erdei, E. and S.M. Torres, A new understanding in the epidemiology of melanoma. Expert review of anticancer therapy, 2010. 10(11): p. 1811-1823. 
12. Gandini, S., et al., Meta-analysis of risk factors for cutaneous melanoma: I. Common and atypical naevi. European journal of cancer, 2005. 41(1): p. 28-44.

13. Veierød, M.B., et al., Sun and solarium exposure and melanoma risk: effects of age, pigmentary characteristics, and nevi. Cancer Epidemiology and Prevention Biomarkers, 2010. 19(1): p. 111-120.

14. Gandini, S., et al., Meta-analysis of risk factors for cutaneous melanoma: III. Family history, actinic damage and phenotypic factors. European journal of cancer, 2005. 41(14): p. 2040-2059.

15. Markovic, S.N., et al. Malignant melanoma in the 21st century, part 1: epidemiology, risk factors, screening, prevention, and diagnosis. in Mayo Clinic Proceedings. 2007. Elsevier.

16. D'Orazio, J., et al., UV radiation and the skin. International journal of molecular sciences, 2013. 14(6): p. $12222-12248$.

17. Kricker, A., et al., Ambient UV, personal sun exposure and risk of multiple primary melanomas. Cancer Causes \& Control, 2007. 18(3): p. 295-304.

18. Wu, S., et al., Long-term ultraviolet flux, other potential risk factors, and skin cancer risk: a cohort study. Cancer Epidemiology and Prevention Biomarkers, 2014.

19. Pfahlberg, A., K.F. Kölmel, and G.F.T.F.S. Group, Timing of excessive ultraviolet radiation and melanoma: epidemiology does not support the existence of a critical period of high susceptibility to solar ultraviolet radiation-induced melanoma. British Journal of Dermatology, 2001. 144(3): p. 471475.

20. Kennedy, C., et al., The influence of painful sunburns and lifetime sun exposure on the risk of actinic keratoses, seborrheic warts, melanocytic nevi, atypical nevi, and skin cancer. Journal of Investigative Dermatology, 2003. 120(6): p. 1087-1093.

21. Ghiasvand, R., et al., Indoor tanning and melanoma risk: long-term evidence from a prospective population-based cohort study. American Journal of Epidemiology, 2017. 185(3): p. 147-156.

22. Colantonio, S., M.B. Bracken, and J. Beecker, The association of indoor tanning and melanoma in adults: systematic review and meta-analysis. Journal of the American academy of dermatology, 2014. 70(5): p. 847-857. e18.

23. Lazovich, D., et al., Indoor tanning and risk of melanoma: a case-control study in a highly exposed population. Cancer Epidemiology and Prevention Biomarkers, 2010: p. 1055-9965. EPI-09-1249.

24. Fritschi, L. and T. Driscoll, Cancer due to occupation in Australia. Australian and New Zealand journal of public health, 2006. 30(3): p. 213-219.

25. Thomas, N.E., et al., Number of nevi and early-life ambient UV exposure are associated with BRAFmutant melanoma. Cancer Epidemiology and Prevention Biomarkers, 2007. 16(5): p. 991-997.

26. Thomas, N.E., M. Berwick, and M. Cordeiro-Stone, Could BRAF mutations in melanocytic lesions arise from DNA damage induced by ultraviolet radiation? Journal of Investigative Dermatology, 2006. 126(8): p. 1693-1696.

27. Poynter, J.N., et al., BRAF and NRAS mutations in melanoma and melanocytic nevi. Melanoma research, 2006. 16(4): p. 267-273. 
28. Rigel, D.S., E.G. Rigel, and A.C. Rigel, Effects of altitude and latitude on ambient UVB radiation. Journal of the American Academy of Dermatology, 1999. 40(1): p. 114-116.

29. Aceituno-Madera, P., et al., Melanoma, altitude, and UV-B radiation. Actas Dermosifiliogr, 2011. 102(3): p. 199-205.

30. Wang, S.Q., et al., Ultraviolet $A$ and melanoma: a review. Journal of the American Academy of Dermatology, 2001. 44(5): p. 837-846.

31. Thomas, N.E., BRAF somatic mutations in malignant melanoma and melanocytic naevi. Melanoma research, 2006. 16(2): p. 97-103.

32. WHO. Global Health Observatory, the data repository. WHO 2015 [11.26.2015]; Available from: http://www.who.int/gho/database/en/.

33. Ferlay, J., et al. GLOBOCAN 2012 v1.0, Cancer Incidence and Mortality Worldwide: IARC CancerBase No. 11 [Internet]. 2013 28.05.2016]; Available from: http://globocan.iarc.fr.

34. Green, A.C., et al., Reduced melanoma after regular sunscreen use: randomized trial follow-up. Journal of Clinical Oncology, 2011. 29(3): p. 257-263.

35. Dennis, L.K., L.E.B. Freeman, and M.J. VanBeek, Sunscreen use and the risk for melanoma: a quantitative review. Annals of internal medicine, 2003. 139(12): p. 966-978.

36. Sober, A., Sunscreens and melanoma: an on-going controversy. Melanoma Research, 2010. 20: p. e6.

37. Bastuji-Garin, S. and T. Diepgen, Cutaneous malignant melanoma, sun exposure, and sunscreen use: epidemiological evidence. British Journal of Dermatology, 2002. 146(s61): p. 24-30.

38. Xie, F., et al., Analysis of association between sunscreens use and risk of malignant melanoma. International journal of clinical and experimental medicine, 2015. 8(2): p. 2378.

39. Gorham, E.D., et al., Do sunscreens increase risk of melanoma in populations residing at higher latitudes? Annals of epidemiology, 2007. 17(12): p. 956-963.

40. Westerdahl, J., et al., Sunscreen use and malignant melanoma. International journal of cancer, 2000. 87(1): p. 145-150.

41. Rueegg, C.S., et al., Challenges in assessing the sunscreen-melanoma association. International journal of cancer, 2019. 144(11): p. 2651-2668.

42. Cho, E., et al., Risk factors and individual probabilities of melanoma for whites. Journal of clinical oncology, 2005. 23(12): p. 2669-2675.

43. Gandini, S., et al., Meta-analysis of risk factors for cutaneous melanoma: II. Sun exposure. European journal of cancer, 2005. 41(1): p. 45-60.

44. Goydos, J.S.S., Steven L. , Acral Lentiginous Melanoma. Cancer Treatment and Research, 2016(167): p. 321-329.

45. Bleyer, W.A., Cancer in older adolescents and young adults: epidemiology, diagnosis, treatment, survival, and importance of clinical trials. Pediatric Blood \& Cancer, 2002. 38(1): p. 1-10.

46. Lasithiotakis, K.G., I.E. Petrakis, and C. Garbe, Cutaneous melanoma in the elderly: epidemiology, prognosis and treatment. Melanoma research, 2010. 20(3): p. 163-170. 
47. Jablonski, N.G. and G. Chaplin, Human skin pigmentation as an adaptation to UV radiation. Proceedings of the National Academy of Sciences, 2010: p. 200914628.

48. Jablonski, N.G. and G. Chaplin, The evolution of human skin coloration. Journal of human evolution, 2000. 39(1): p. 57-106.

49. Jablonski, N.G. and G. Chaplin, Human skin pigmentation as an adaptation to UV radiation. Proceedings of the National Academy of Sciences, 2010. 107(Supplement 2): p. 8962-8968.

50. Borradale, D.C. and M.G. Kimlin, Folate degradation due to ultraviolet radiation: possible implications for human health and nutrition. Nutrition reviews, 2012. 70(7): p. 414-422.

51. Ferlay, J., et al., Cancer incidence and mortality worldwide: sources, methods and major patterns in GLOBOCAN 2012. Int J Cancer, 2015. 136(5): p. E359-86.

52. Relethford, J.H., Hemispheric difference in human skin color. American Journal of Physical Anthropology: The Official Publication of the American Association of Physical Anthropologists, 1997. 104(4): p. 449-457.

53. Diamond, J., Evolutionary biology: geography and skin colour. Nature, 2005. 435(7040): p. 283.

54. Brace, C., M. Henneberg, and J. Relethford. Skin color as an index of timing in human evolution. in American Journal of Physical Anthropology. 1999,28. Am J Phys Anthopol Suppl.

55. The World Bank Group. World Bank Open Data. 2016 12.07.2016]; Available from: http://data.worldbank.org/.

56. Cancer Research UK. Risks and causes of melanoma. 15 Dec 201515 May 2018]; Available from: http://about-cancer.cancerresearchuk.org/about-cancer/melanoma/risks-causes.

57. Sharp, L., et al., Risk of several cancers is higher in urban areas after adjusting for socioeconomic status. Results from a two-country population-based study of 18 common cancers. Journal of Urban Health, 2014. 91(3): p. 510-525.

58. Allender, S., et al., Quantification of urbanization in relation to chronic diseases in developing countries: a systematic review. J Urban Health, 2008. 85(6): p. 938-951.

59. Moore, M., P. Gould, and B.S. Keary, Global urbanization and impact on health. International journal of hygiene and environmental health, 2003. 206(4): p. 269-278.

60. WHO. Urbanization and health. WHO 2010 2010-12-07 15:20:05 2 November 2016]; Available from: http://www.who.int/bulletin/volumes/88/4/10-010410/en/.

61. Budnik, A. and M. Henneberg, Worldwide increase of obesity is related to the reduced opportunity for natural selection. PloS one, 2017. 12(1): p. e0170098.

62. Project, M.M.M. Epidemiology. 2007-2015 09 June 2018].

63. Chen, S.T., A.C. Geller, and H. Tsao, Update on the epidemiology of melanoma. Current dermatology reports, 2013. 2(1): p. 24-34.

64. Park, S.L., et al., Risk factors for malignant melanoma in white and non-white/non-African American populations: the multiethnic cohort. Cancer Prevention Research, 2012. 
65. American Cancer Society, I., „. Key Statistics for Melanoma Skin Cancer. 201822 May 2018]; Available from: https://www.cancer.org/cancer/melanoma-skin-cancer/about/key-statistics.html.

66. European Commission eurostat, , . Statistics Explained. 201715 May 2018]; Available from: http://ec.europa.eu/eurostat/statistics-explained/index.php/Main_Page.

67. Carleton, S.C., The Races of Europe. April 1939, New York: The Macmillan Company.

68. Buettner, P.G. and R. MacLennan, Geographical variation of incidence of cutaneous melanoma in Queensland. Australian Journal of Rural Health, 2008. 16(5): p. 269-277.

69. WHO, Global Health Risks Mortality and Burden of Disease Attributable to Selected Major Risks. 2009, Geneva: Geneva : World Health Organization.

70. Ward, W.H. and J.M. Farma, Chapter 6. Clinical Presentation and Staging of Melanoma, in Cutaneous Melanoma: Etiology and Therapy [Internet]. 2017, Codon Publications: Brisbane (AU).

71. Ghiasvand, R., et al., Association of phenotypic characteristics and UV radiation exposure with risk of melanoma on different body sites. JAMA dermatology, 2019. 155(1): p. 39-49.

72. Gandini, S., et al., Epidemiological evidence of carcinogenicity of sunbed use and of efficacy of preventive measures. Journal of the European Academy of Dermatology and Venereology, 2019. 33: p. 57-62.

73. Savoye, I., et al., Patterns of ultraviolet radiation exposure and skin cancer risk: the E3N-SunExp study. Journal of epidemiology, 2017: p. JE20160166.

74. Stenehjem, J.S., et al., Ultraviolet radiation and skin cancer risk in offshore workers. Occupational Medicine, 2017. 67(7): p. 569-573.

75. Kanavy, H.E. and M.R. Gerstenblith. Ultraviolet radiation and melanoma. in Seminars in cutaneous medicine and surgery. 2011. Frontline Medical Communications.

76. Armstrong, B.K., How sun exposure causes skin cancer: an epidemiological perspective, in Prevention of skin cancer. 2004, Springer. p. 89-116.

77. Pfeifer, G.P. and A. Besaratinia, UV wavelength-dependent DNA damage and human non-melanoma and melanoma skin cancer. Photochemical \& photobiological sciences, 2012. 11(1): p. 90-97.

78. Mahendraraj; K., et al., Malignant Melanoma in African-Americans- A Population-Based Clinical Outcomes Study Involving 1106 African-American Patients from the Surveillance, Epidemiology, and End Result (SEER) Database (1988-2011). Medicine, 2017. 96(15):e6258).

79. Torres, S.M., et al., DNA repair variants, indoor tanning, and risk of melanoma. Pigment cell \& melanoma research, 2013. 26(5): p. 677-684.

80. Page, C.M., et al., Lifetime Ultraviolet Radiation exposure and DnA Methylation in Blood Leukocytes: the norwegian Women and cancer Study. Scientific reports, 2020. 10(1): p. 1-8.

81. Al Emran, A., et al., Targeting DNA methylation and EZH2 activity to overcome melanoma resistance to immunotherapy. Trends in immunology, 2019. 40(4): p. 328-344.

82. Micevic, G., N. Theodosakis, and M. Bosenberg, Aberrant DNA methylation in melanoma: biomarker and therapeutic opportunities. Clinical epigenetics, 2017. 9(1): p. 1-15. 
83. Yuen, A. and N. Jablonski, Vitamin D: in the evolution of human skin colour. Medical hypotheses, 2010. 74(1): p. 39-44.

84. Meredith, P. and J. Riesz, Radiative relaxation quantum yields for synthetic eumelanin. Photochemistry and photobiology, 2004. 79(2): p. 211-216.

85. López, S., et al., The interplay between natural selection and susceptibility to melanoma on allele 374F of SLC45A2 gene in a South European population. PloS one, 2014. 9(8): p. e104367.

86. Bell, N.H., et al., Evidence for alteration of the vitamin D-endocrine system in obese subjects. The Journal of clinical investigation, 1985. 76(1): p. 370-373.

87. Kennel, K.A., M.T. Drake, and D.L. Hurley. Vitamin D deficiency in adults: when to test and how to treat. in Mayo Clinic Proceedings. 2010. Elsevier.

88. Sturm, R.A. and D.L. Duffy, Human pigmentation genes under environmental selection. Genome biology, 2012. 13(9): p. 248.

89. You, W. and H. M, Cancer incidence increasing globally: The role of relaxed natural selection. Evol Appl., 2017. 00:1-13.

90. Greaves, M., Was skin cancer a selective force for black pigmentation in early hominin evolution? Proc. R. Soc. B, 2014. 281(1781): p. 20132955.

91. Ossio, R., et al., Melanoma: a global perspective. Nature Reviews Cancer, 2017. 17(7): p. 393-394.

92. Rampen, F.H. and E. Fleuren, Melanoma of the skin is not caused by ultraviolet radiation but by a chemical xenobiotic. Medical hypotheses, 1987. 22(4): p. 341-346.

93. Goldstein, A.M. and M.A. Tucker, Genetic epidemiology of cutaneous melanoma: a global perspective. Archives of dermatology, 2001. 137(11): p. 1493-1496.

94. Mucci, L.A., et al., Familial risk and heritability of cancer among twins in Nordic countries. Jama, 2016. 315(1): p. 68-76.

95. Torricelli, C., Análise funcional do polimorfismo c. 938-325G>A do gene" MITF", envolvido com a melanogênese, em melanoma cutâneo. 2019.

96. Oliveira, C.d., Identificação de genes de suscetibilidade herdada para o melanoma cutâneo por genotipagem em larga escala. 2017.

97. McMeniman, E., et al., The interplay of sun damage and genetic risk in Australian multiple and single primary melanoma cases and controls. British Journal of Dermatology, 2019.

98. Visconti, A., et al., Genome-wide association study in 176,678 Europeans reveals genetic loci for tanning response to sun exposure. Nature communications, 2018. 9(1): p. 1-7.

99. Hernando, B., et al., Sex-specific genetic effects associated with pigmentation, sensitivity to sunlight, and melanoma in a population of Spanish origin. Biology of sex differences, 2016. 7(1): p. 17.

100. Fu, S., et al., DNA methylation/hydroxymethylation in melanoma. Oncotarget, 2017. 8(44): p. 78163.

101. Bataille, V. and E. de Vries, Melanoma-Part 1: epidemiology, risk factors, and prevention. BMJ (Clinical research ed.), 2008. 337. 
102. Australian Government Department of Health, Australian Government Response to House of Representatives Standing Committee on Health Report - Skin Cancer in Australia: Our National Cancer, Australian Government Department of Health, Editor. 2014, Australian Government Department of Health,: Online.

103. Glasziou, P.P., et al., Estimating the magnitude of cancer overdiagnosis in Australia. Medical Journal of Australia, 2020. 212(4): p. 163-168.

104. Cho, H.G., et al., Frequent basal cell cancer development is a clinical marker for inherited cancer susceptibility. JCl insight, 2018. 3(15).

105. American Cancer Society. Risk Factors for Melanoma Skin Cancer. 2016 27/01/2019]; Available from: https://www.cancer.org/cancer/melanoma-skin-cancer/causes-risks-prevention/riskfactors.html.

106. Wassberg, C., et al., Second primary cancers in patients with squamous cell carcinoma of the skin: a population-based study in Sweden. International journal of cancer, 1999. 80(4): p. 511-515.

107. Milán, T., et al., Subsequent primary cancers after basal-cell carcinoma: a nationwide study in Finland from 1953 to 1995. International journal of cancer, 2000. 87(2): p. 283-288.

108. Frisch, M., et al., Risk for subsequent cancer after diagnosis of basal-cell carcinoma: a populationbased, epidemiologic study. Annals of Internal Medicine, 1996. 125(10): p. 815-821.

109. You, W.-P. and M. Henneberg, Type 1 diabetes prevalence increasing globally and regionally: the role of natural selection and life expectancy at birth. BMJ Open Diabetes Research \& Care, 2016. 4(1): p. e000161.

110. You, W. and M. Henneberg, Relaxed natural selection contributes to global obesity increase more in males than in females due to more environmental modifications in female body mass. PloS one, 2018. 13(7): p. e0199594.

111. You, W., I. Symonds, and M. Henneberg, Low fertility may be a significant determinant of ovarian cancer worldwide: an ecological analysis of cross-sectional data from 182 countries. Journal of ovarian research, 2018. 11(1): p. 68.

112. You, W., et al., Decreasing Birth Rate Determining Worldwide Incidence and Regional Variation of Female Breast Cancer. Advances in Breast Cancer Research, 2018. 07(01): p. 1-14.

113. You, W., et al., Greater family size is associated with less cancer risk: an ecological analysis of 178 countries. BMC cancer, 2018. 18(1): p. 924.

114. Field, S. and J.A. Newton-Bishop, Melanoma and vitamin D. Molecular oncology, 2011. 5(2): p. 197214.

115. Osborne, J. and P. Hutchinson, Vitamin D and systemic cancer: is this relevant to malignant melanoma? British Journal of Dermatology, 2002. 147(2): p. 197-213.

116. Grant, W.B., An ecological study of cancer incidence and mortality rates in France with respect to latitude, an index for vitamin D production. Dermato-endocrinology, 2010. 2(2): p. 62-67. 
117. Fang, S., et al., Association of vitamin D levels with outcome in patients with melanoma after adjustment for C-reactive protein. Journal of Clinical Oncology, 2016. 34(15): p. 1741.

118. Sondak, V.K., B. Mclver, and P.A. Kanetsky, Vitamin D and melanoma: what do we tell our patients? 2016, American Society of Clinical Oncology.

119. GREEN, A. and N.G. Martin, Measurement and perception of skin colour in a skin cancer survey. British Journal of Dermatology, 1990. 123(1): p. 77-84.

120. Wulf, H. and J. Lock-Andersen, Measurement of constitutive skin phototypes, in Skin cancer and UV radiation. 1997, Springer. p. 169-180.

121. Lock-Andersen, J., K.T. Drzewiecki, and H.C. Wulf, Eye and Hair Colour, Skin Type, and Constitutive Skin Pigmentation as Risk Factors for Basal Cell Carcinoma and Cutaneous Malignant Melanoma. ACTA DERMATOVENEREOLOGICA-STOCKHOLM-, 1999. 79: p. 74-80.

122. Lock-Andersen, J. and H. Wulf, Seasonal variation of skin pigmentation. Acta dermato-venereologica, 1997. 77(3): p. 219-221.

123. Lancaster, H. and J. Nelson, Sunlight as a cause of melanoma; a clinical survey. The Medical journal of Australia, 1957. 44(14): p. 452.

124. Evans, R.D., et al., Risk Factors for the Development of Malignant Melanoma-l: Review of CaseControl Studies. The Journal of dermatologic surgery and oncology, 1988. 14(4): p. 393-408.

125. Bliss, J.M., et al., Risk of cutaneous melanoma associated with pigmentation characteristics and freckling: Systematic overview of 10 case-control studies. International journal of cancer, 1995. 62(4): p. 367-376.

126. Alexandrov, L.B., et al., Signatures of mutational processes in human cancer. Nature, 2013. 500(7463): p. 415-421.

127. Tate, J.G., et al., COSMIC: the catalogue of somatic mutations in cancer. Nucleic acids research, 2019. 47(D1): p. D941-D947.

128. Perduca, V., et al., Stem cell replication, somatic mutations and role of randomness in the development of cancer. European journal of epidemiology, 2019. 34(5): p. 439-445.

129. Svensson, E.I. and D. Berger, The role of mutation bias in adaptive evolution. Trends in ecology \& evolution, 2019. 34(5): p. 422-434.

130. Beck, C.R., et al., Megabase length hypermutation accompanies human structural variation at $17 p 11$. 2. Cell, 2019. 176(6): p. 1310-1324. e10.

131. Li, Y., et al., Patterns of somatic structural variation in human cancer genomes. Nature, 2020. 578(7793): p. 112-121.

132. Funnell, T., et al., Integrated structural variation and point mutation signatures in cancer genomes using correlated topic models. PLoS computational biology, 2019. 15(2): p. e1006799.

133. Brázda, V. and M. Fojta, The Rich World of p53 DNA Binding Targets: The Role of DNA Structure. International journal of molecular sciences, 2019. 20(22): p. 5605. 
134. Zhang, Y., et al., Global impact of somatic structural variation on the DNA methylome of human cancers. Genome biology, 2019. 20(1): p. 209.

135. Stephan, C.N. and M. Henneberg, Medicine may be reducing the human capacity to survive. Medical Hypotheses, 2001. 57(5): p. 633-37.

136. Henneberg, M. and J. Piontek, Biological state index of human groups. Przeglad Anthropologiczny, 1975. XLI: p. 191-201.

137. Henneberg, M., Reproductive possibilities and estimations of the biological dynamics of earlier human populations. Journal of Human Evolution, 1976. 5: p. 41-8.

\section{Tables}

Table 1 Worldwide relationships between melanoma (C43) incidence and UVR levels

\begin{tabular}{|c|c|c|c|c|c|c|c|}
\hline & \multicolumn{2}{|c|}{$\begin{array}{c}\text { Table 1-1: } \\
\text { Nonparametric } \\
\text { (Spearman's) }\end{array}$} & \multicolumn{2}{|c|}{$\begin{array}{c}\text { Table 1-2: } \\
\text { Partial } \\
\text { Correlation }\end{array}$} & \multicolumn{3}{|c|}{$\begin{array}{l}\text { Table 1-3: } \\
\text { Stepwise multiple linear regression }\end{array}$} \\
\hline & $\rho$ & $\mathrm{n}$ & $\mathrm{r}$ & $\mathrm{df}$ & Rank & Independent Variables & Adjusted $\mathrm{R}^{2}$ \\
\hline $\begin{array}{l}\text { UVR exposure } \\
\text { (Negative) }\end{array}$ & $-0.515^{* * *}$ & 171 & $-0.513^{* * *}$ & 163 & 1 & $\begin{array}{l}\text { UVR Exposure } \\
\text { (Negative) }\end{array}$ & 0.301 \\
\hline Skin reflectance & $0.325^{\# \#}$ & 35 & 0.153 & 19 & 2 & $\mathrm{I}_{\mathrm{bs}}$ & 0.321 \\
\hline GDP PPP & $0.383^{* * *}$ & 172 & - & - & 3 & Ageing & 0.363 \\
\hline $\mathrm{I}_{\mathrm{bs}}$ & $0.456^{* * *}$ & 172 & - & - & 4 & GDP PPP & Insignificant \\
\hline Ageing & $0.415^{* * *}$ & 174 & - & - & 5 & Urbanization & Insignificant \\
\hline Urbanization & $0.354^{* * *}$ & 178 & - & - & & & \\
\hline
\end{tabular}

Significance level of correlation: $* \mathrm{p}<0.05, * * \mathrm{p}<0.01, * * * \mathrm{p}<0.001$

\# Keeping intake of GDP PPP, $\mathrm{I}_{\mathrm{bs}}$, life e (60) and urbanization constant.

\#\# $\mathrm{p}=0.057$, marginally significant at the level of $\mathrm{p}<0.05$

Data sources: Melanoma of skin incidence rate from the International Agency for Research on Cancer, WHO agent in cancer research; UVR, expressed as the average daily ambient ultraviolet radiation level (in $\mathrm{J} / \mathrm{m}^{2}$ ) \& ageing, indexed by life $\mathrm{e}_{60}$ from the World Health Organization; Skin reflectance from previous publication [54]; GDP PPP \& Urbanization from the World Bank; $\mathrm{I}_{\mathrm{bs}}$ from the previous publication [61].

Table 2 Worldwide relationships between melanoma (C43) incidence and Europeans \% . 
Table 3-2:

Table 3-1:

Nonparametric (Spearman's)
Partial Correlation
Table 3-3:

Stepwise multiple linear regression

\begin{tabular}{|c|c|c|c|c|c|c|c|}
\hline & & \\
\hline & $\rho$ & $\mathrm{n}$ & $\mathrm{r}$ & $\mathrm{df}$ & Rank & Independent Variables & Adjusted $\mathrm{R}^{2}$ \\
\hline Europeans\% & $0.711^{* * *}$ & 127 & $0.477^{* * *}$ & 121 & 1 & UVR (Negative) & 0.299 \\
\hline UVR & $-0.699^{* * *}$ & 135 & $-0.498^{* * *}$ & 119 & 2 & Europeans \% & 0.336 \\
\hline GDP PPP & $0.642^{* * *}$ & 129 & - & - & 3 & $\mathrm{I}_{\mathrm{bs}}$ & 0.400 \\
\hline $\mathrm{I}_{\mathrm{bs}}$ & $0.736^{* * *}$ & 129 & - & - & 4 & Ageing & 0.470 \\
\hline Ageing & $0.595^{* * *}$ & 130 & - & - & 5 & GDPPPP 2010 & 0.487 \\
\hline Urbanization & $0.595^{* * *}$ & 134 & - & - & $\begin{array}{c}\text { Not } \\
\text { ranked, }\end{array}$ & $\begin{array}{l}\text { Urbanisation } \\
\text { explained }\end{array}$ & $\begin{array}{l}\text { by other } \\
\text { variables }\end{array}$ \\
\hline
\end{tabular}

Correlation significance level: ${ }^{* * *} \mathrm{p}<0.001,{ }^{* *} \mathrm{p}<0.01,{ }^{*} \mathrm{p}<0.05$

- Control variable

Data sources: Europeans \% (percentage of European descendants ) from the corresponding government statistics or various publications; Melanoma of skin incidence rate from the International Agency for Research on Cancer, WHO agent in cancer research; UVR, expressed as the average daily ambient ultraviolet radiation level (in J/m²) \& ageing (life $\mathrm{e}_{60}$ ) from the World Health Organization; GDP PPP \& Urbanization from the World Bank; $\mathrm{I}_{\mathrm{bs}}$ from the previous publication [61].

Table 3 Relationships between depigmentation level and melanoma (C43) incidence within WHO Europe Region 


\begin{tabular}{|c|c|c|c|c|c|c|c|c|}
\hline & \multicolumn{2}{|c|}{$\begin{array}{l}\text { Table 3-1 } \\
\text { Nonparametric (Spearman's) }\end{array}$} & \multicolumn{2}{|c|}{$\begin{array}{c}\text { Table 3-2 } \\
\text { Partial } \\
\text { Correlation }\end{array}$} & \multicolumn{2}{|c|}{$\begin{array}{c}\text { Table 3-3 } \\
\text { Partial } \\
\text { Correlation }\end{array}$} & \multicolumn{2}{|c|}{$\begin{array}{c}\text { Table 3-4 } \\
\text { Partial } \\
\text { Correlation }\end{array}$} \\
\hline & $\rho$ & $\mathrm{n}$ & $\mathrm{r}$ & $\mathrm{df}$ & $\mathrm{r}$ & $\mathrm{df}$ & $\mathrm{r}$ & $\mathrm{df}$ \\
\hline Depigmentation & $0.696^{* * *}$ & 48 & $0.512^{* * *}$ & 44 & $0.315^{* *}$ & 41 & - & - \\
\hline UVR (Negative) & $-0.677^{* * *}$ & 50 & $-0.425^{* *}$ & 42 & - & - & -0.006 & 41 \\
\hline GDP PPP & $0.823^{* * *}$ & 50 & - & - & - & - & - & - \\
\hline $\mathrm{I}_{\mathrm{bs}}$ & $0.769^{* * *}$ & 50 & - & - & - & - & - & - \\
\hline Ageing & $0.675^{* * *}$ & 50 & - & - & - & - & - & - \\
\hline Urbanization & $0.631^{* * *}$ & 50 & - & - & - & - & - & - \\
\hline
\end{tabular}

- Variable kept statistically constant.

Data sources: Melanoma of skin incidence rate from the International Agency for Research on Cancer, WHO agent in cancer research; Pigmentation from the previous publication [74]; UVR, expressed as the average daily ambient ultraviolet radiation level (in $\mathrm{J} / \mathrm{m}^{2}$ ) \& ageing (life e60) from the World Health Organization; GDP PPP \& Urbanization from the World Bank; $\mathrm{I}_{\mathrm{bs}}$ from the previous publication [61]).

Table 4-5: Stepwise multiple linear regression $(\mathrm{n}=50)$

\begin{tabular}{lll}
\hline Rank & Independent Variables & Adjusted $\mathrm{R}^{2}$ \\
\hline 1 & GDP PPP & 0.642 \\
2 & Depigmentation & 0.720 \\
3 & $\mathrm{I}_{\mathrm{bs}}$ & 0.768 \\
4 & Ageing & Insignificant \\
5 & Urbanization & Insignificant \\
6 & UVR levels & Non-predictor
\end{tabular}

Stepwise multiple linear regression modelling was reported. Contribution of variables is listed in order of how much they contribute to Melanoma of skin incidence.

Data sources: Melanoma of skin incidence rate from the International Agency for Research on Cancer, WHO agent in cancer research; Europeans \% (percentage of European diaspora/descendants) from the corresponding government statistics or various publications; Pigmentation from the previous publication [74]; UVR, expressed as the average daily ambient ultraviolet radiation level (in $\mathrm{J} / \mathrm{m}^{2}$ ) \& ageing (life e60) from the WHO; GDP PPP \& Urbanization from the World Bank; Ibs from the previous publication [61]. 


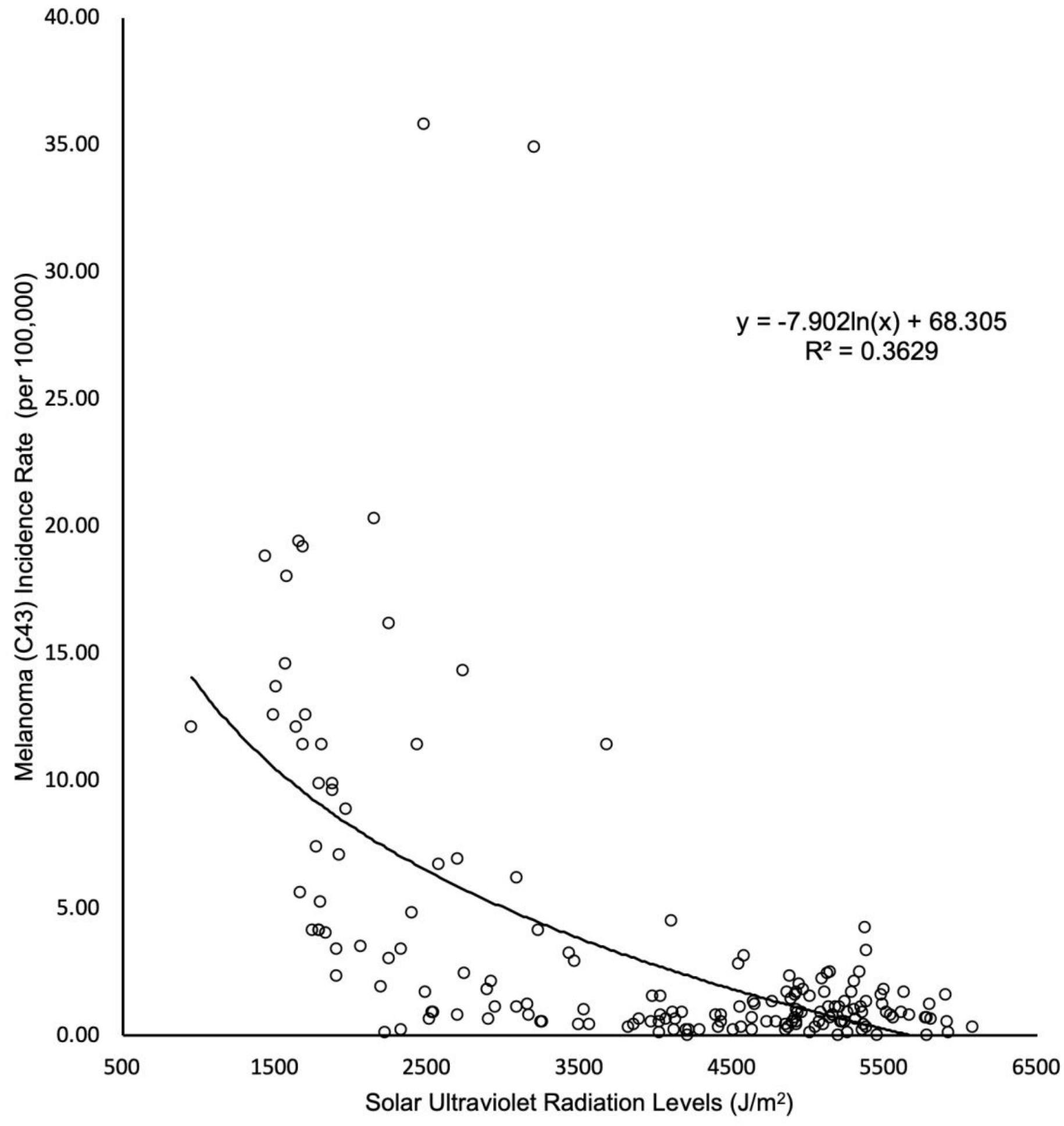

Figure 1

Relationship between low solar ultraviolet radiation levels and malignant melanoma of skin (C43) incidence rate worldwide Legend: Data sources: Melanoma of skin incidence rate from the International Agency for Research on Cancer, WHO agent in cancer research; UVR, expressed as the average daily ambient ultraviolet radiation level (in $\mathrm{J} / \mathrm{m} 2$ ) 


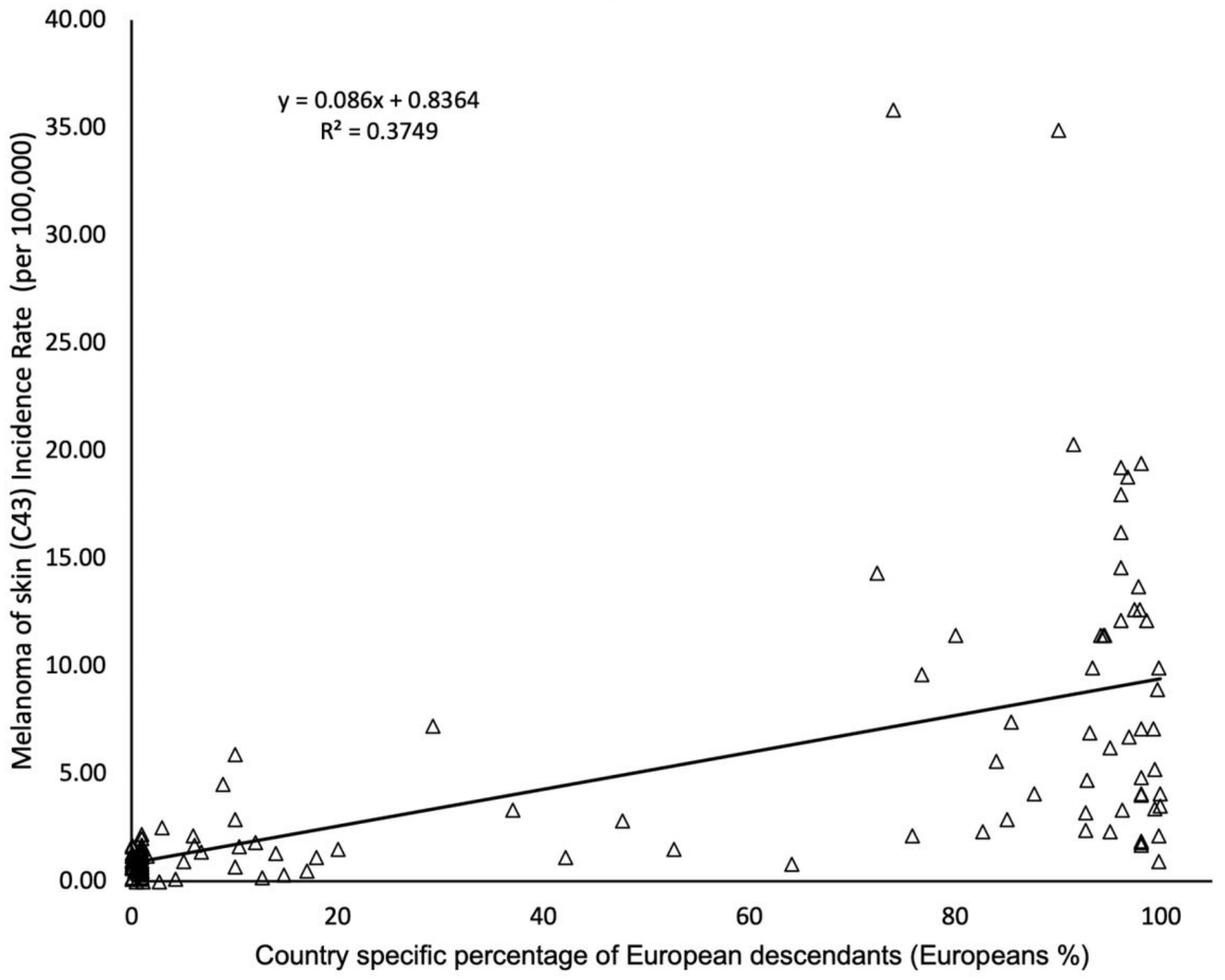

Figure 2

Population-level relationship between country specific percentage of European descendants and malignant melanoma of skin (C43) incidence rate Legend: Data sources: Melanoma of skin incidence rate from the International Agency for Research on Cancer, WHO agent in cancer research; Europeans \% (percentage of European diaspora/descendants) from the corresponding government statistics or various publications; UVR, expressed as the average daily ambient ultraviolet radiation level (in $\mathrm{J} / \mathrm{m} 2$ ) \& ageing (life e60) from the WHO. 


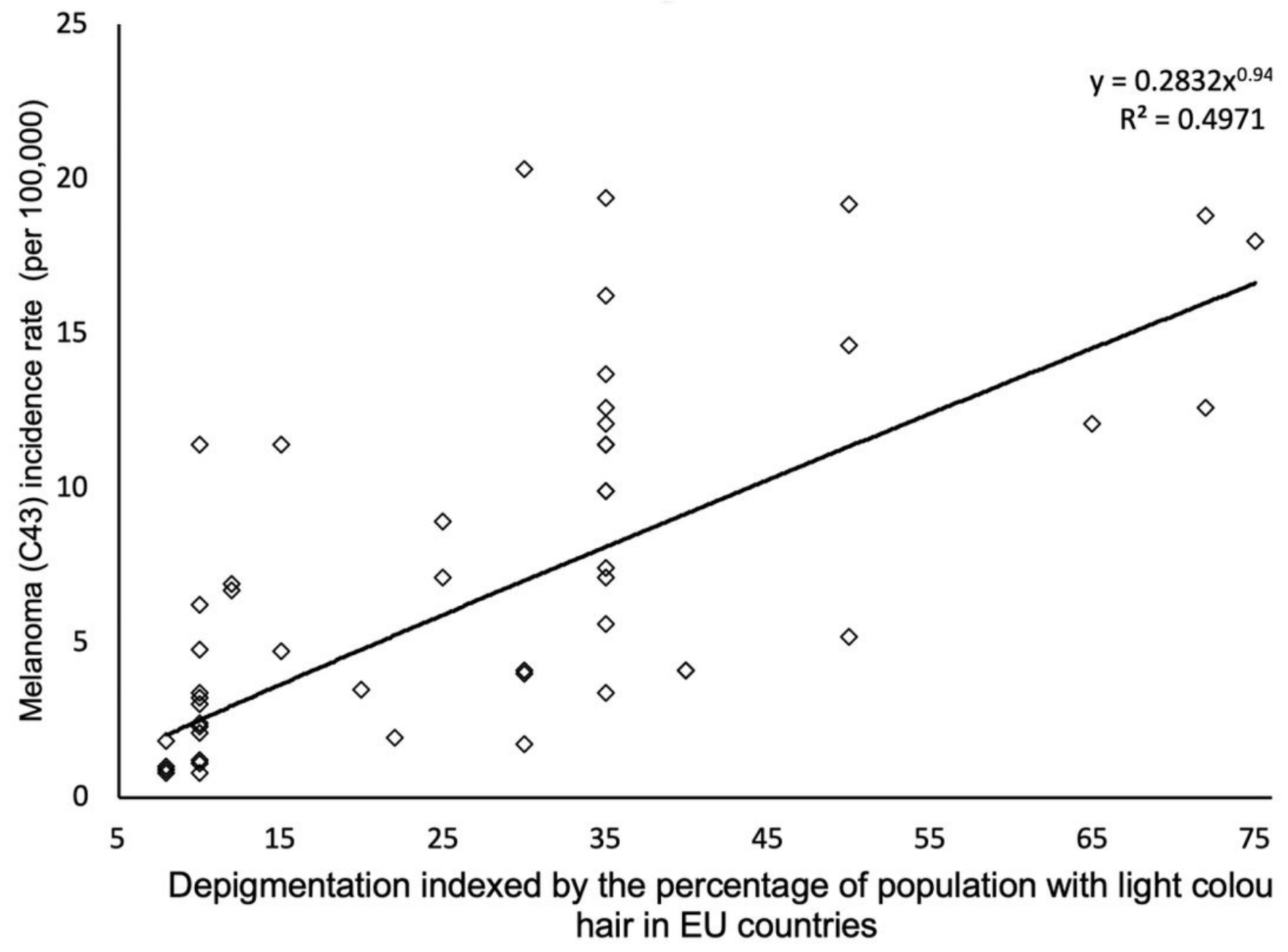

Figure 3

Relationship between melanoma of skin (C43) incidence and depigmentation level y. Legend: Data sources: Melanoma of skin incidence rate from the International Agency for Research on Cancer, WHO agent in cancer research; Pigmentation from the previous publication [74]; UVR, expressed as the average daily ambient ultraviolet radiation level (in $\mathrm{J} / \mathrm{m} 2$ ). 